\title{
Desenvolvendo o cálculo mental e as 4 operações com o uso do software educativo Tux of the Math Comand.
}

\author{
Claudiomir Feustler Rodrigues de Siqueira - PPGENSIMAT - UFRGS \\ claudiomir.siqueira@ibiruba.ifrs.edu.br
}

\begin{abstract}
Resumo
Este artigo apresenta resultados de um projeto de ensino de matemática com o uso de software educativo, o qual visava motivar e reforçar o aprendizado de 96 alunos dos $6^{\text {os }}$ anos de uma escola municipal na cidade de Novo HamburgoRS. No início do estudo o índice de rejeição à matemática estava muito alto e os alunos apresentavam diversas dificuldades na resolução das atividades. Também foi observado que o aprendizado estava muito abaixo do ano escolar em que se encontravam. Os resultados indicam uma significativa mudança de atitude dos alunos quanto à motivação demonstrada nas participações em aula e também na qualidade das resoluções das atividades.
\end{abstract}

Palavras-Chave: software educativo, cálculo mental, motivação, ensino, aprendizagem, matemática.

\begin{abstract}
This article presents results of a project of teaching mathematics using educational software, which aimed to motivate and reinforce learning of 96 students from 6th year of a municipal school in the town of Novo Hamburgo-RS. At baseline the rejection rate was very high in mathematics and the students had difficulties in addressing the various activities. It was also noted that learning was well below the school year in which they were. The results indicate a significant change in attitude and motivation of students demonstrated in their participation in class and also the quality of the resolutions of the activities.
\end{abstract}

Keywords: educational software, mental arithmetic, motivation, teaching, learning, mathematics.

\section{Introdução}

O alto índice de reprovação no ensino fundamental é atribuído à disciplina de Matemática. Frente a esse fato, a busca por práticas docentes inovadoras se faz necessária, justificando a proposta de utilização de softwares matemáticos no processo de ensino aprendizagem.

Diante desse cenário Araújo (2007) destaca que:

Muitas pesquisas em Educação Matemática procuram mostrar caminhos na tentativa de reverter os problemas relacionados à disciplina. Sabemos que os problemas existem, porém, reverter este quadro não é fácil. Em relação às disciplinas escolares a Matemática aparece como um componente curricular que tem 
aterrorizado muitos estudantes, causando reprovações e prejudicando o rendimento dos alunos.

Trabalhando com alunos do $6^{\circ}$ ano, de uma escola municipal de Novo Hamburgo-RS, observou-se muitas dificuldades na resolução de cálculos mentais, por exemplo, a soma de dois números menores do que 10, qual número que adicionado a outro se obtém resultado 10? Além disso, a partir da avaliação diagnóstica, constatou-se que $93,75 \%$ dos alunos não resolvia satisfatoriamente uma das quatro operações matemática em nível de $5^{\circ}$ ano.

Visando a melhora da qualidade do processo de ensino-aprendizagem e uma prevenção de tais deficiências, surgiu esse projeto com o objetivo de desenvolver o cálculo mental dos alunos, focando a habilidade de assimilar e saber o resultado de cálculos simples de forma rápida. Estimulando habilidades e estratégias do cálculo mental e diminuindo a dependência da contagem nos dedos e do uso dos 'risquinhos' para a resolução de cálculos, com isso melhorando a auto-estima e a motivação para estudar Matemática.

Indo ao encontro de Fabre, Tarouco e Tamusiuna(2003) que afirmam que as tecnologias da informação provocaram mudanças em várias esferas da sociedade. Capazes de trazerem novas maneiras de ensino e aprendizagem. Além disso, os objetos educacionais se destacam devido à acessibilidade, interoperabilidade e durabilidade.

Nesse mesmo contexto os autores Strelow e Del Pino (2009) destacam que:

Os professores de Matemática vivem em busca de despertar e estimular nos alunos o prazer de aprender esta disciplina, ainda que, dentre os demais componentes curriculares, a Matemática desempenhe tradicionalmente um problema para os estudantes.

O projeto Cálculo mental e as 4 operações com o uso do software educativo - Tux of the Math Comand trabalhou com os seguintes conteúdos e competências descritos pelos PCNs previstos para o $1^{0}$ ciclo do Ensino Fundamental:

- Cálculos de adição, subtração, multiplicação e divisão por meio de estratégias pessoais e algumas técnicas convencionais;

- Desenvolvimento de procedimentos e habilidades de cálculo mental; 
- Organização dos fatos básicos das operações pela identificação de regularidades e propriedades;

- Utilização da decomposição das escritas numéricas para a realização do cálculo mental exato e aproximado;

- Desenvolvimento de atitudes favoráveis para a aprendizagem de Matemática;

- Confiança na própria capacidade para elaborar estratégias pessoais diante de situações-problema;

- Valorização da troca de experiências com seus pares como forma de aprendizagem;

- Interesse e curiosidade por conhecer diferentes estratégias de cálculo.

\section{Materiais e Métodos}

Tux of the Math Comand é um software gratuito, em vários idiomas, disponível para Linux, Mac Os e Windows (2000, XP, Vista e 7), é produzido pela Tux4 kids, seu download pode ser feito em <http://tux4kids.alioth.debian. org/tuxmath/> ou <http://www.baixaki.com.br/download/tux-of-the-math-com mand.htm > e neste estudo foi utilizada a versão 1.71 .

A escolha deste software ocorreu por ele ser gratuito e ter uma avaliação considerada de muito boa qualidade quando o avaliamos segundo critérios de Campos(1994):

Planilhas de Avaliação do Software

\begin{tabular}{|l|c|c|c|c|}
\hline \multicolumn{1}{|c|}{ Características Pedagógicas } & Ótimo & Regular & Ruim & $\begin{array}{c}\text { Não } \\
\text { Identificado }\end{array}$ \\
\hline Possui elementos motivadores? & $\mathrm{X}$ & & & \\
\hline $\begin{array}{l}\text { O software fornece seqüências explicativas } \\
\text { para as respostas não adequadas? }\end{array}$ & & & & $\mathrm{X}$ \\
\hline O software possui telas explicativas? & & & & $\mathrm{X}$ \\
\hline $\begin{array}{l}\text { O programa resiste a respostas inadequadas } \\
\text { (como por exemplo, digitar teclas erradas)? }\end{array}$ & $\mathrm{X}$ & & & \\
\hline O vocabulário está adequado ao usuário? & $\mathrm{X}$ & & & \\
\hline $\begin{array}{l}\text { Existem diferentes tipos de mensagens de erro } \\
\text { para o usuário no decorrer do programa? }\end{array}$ & $\mathrm{X}$ & & & \\
\hline $\begin{array}{l}\text { A diagramação da tela é adequada quanto a } \\
\text { colocação de títulos, figuras, textos e } \\
\text { comandos? }\end{array}$ & $\mathrm{X}$ & & & \\
\hline $\begin{array}{l}\text { O aluno pode selecionar o nível de dificuldade } \\
\text { desejado? }\end{array}$ & $\mathrm{X}$ & & & $\mathrm{X}$ \\
\hline $\begin{array}{l}\text { O programa fornece seqüências explicativas } \\
\text { para as respostas erradas? }\end{array}$ & & & & \\
\hline As seqüências ou módulos de apresentação & $\mathrm{X}$ & & & \\
\hline
\end{tabular}

V. $9 \mathrm{~N}^{\mathrm{o}}$ 2, dezembro, 2011 


\begin{tabular}{|l|l|l|l|c|}
\hline dos conceitos são variadas? & & & & \\
\hline $\begin{array}{l}\text { O programa apresenta os escores do } \\
\text { desempenho do aluno? }\end{array}$ & $\mathrm{x}$ & & & \\
\hline O uso é agradável ? & & & & $\mathrm{x}$ \\
\hline
\end{tabular}

Tabela 01: Planilha de avaliação das características pedagógicas do software

\begin{tabular}{|l|c|c|c|c|}
\hline Características de Interface e de Conteúdo & Ótimo & Regular & Ruim & $\begin{array}{c}\text { Não } \\
\text { Identificado }\end{array}$ \\
\hline O conteúdo está correto? & $\mathrm{x}$ & & & \\
\hline A gramática e a ortografia estão corretas? & $\mathrm{x}$ & & & \\
\hline $\begin{array}{l}\text { Os ícones ou comandos são explicados } \\
\text { claramente? }\end{array}$ & $\mathrm{x}$ & & & \\
\hline $\begin{array}{l}\text { O ritmo de apresentação das telas favorece a } \\
\text { leitura e compreensão do conteúdo? }\end{array}$ & $\mathrm{x}$ & & & \\
\hline $\begin{array}{l}\text { As telas são atraentes, fazendo uso } \\
\text { satisfatório de ilustrações? }\end{array}$ & $\mathrm{x}$ & & & \\
\hline $\begin{array}{l}\text { As animações favorecem a compreensão do } \\
\text { conteúdo do programa? }\end{array}$ & $\mathrm{x}$ & & & \\
\hline $\begin{array}{l}\text { O uso de cores favorece a legibilidade do } \\
\text { programa? }\end{array}$ & $\mathrm{x}$ & & & \\
\hline Os recursos sonoros são adequados? & & $\mathrm{x}$ & & \\
\hline Os textos apresentados na tela são claros? & $\mathrm{x}$ & & & \\
\hline Tabel 02: Plana de avalaço das caractsicas
\end{tabular}

Tabela 02: Planilha de avaliação das características de interface e de conteúdo do software

O Tux of the Math Comand é um software educativo desenvolvido sob a ótica comportamentalista, onde estão evidenciados os seguintes aspectos apontados por Campos, Costa e Santos(2010) que:

o software comportamentalista é desenvolvido para uma área e nível específicos, uma vez que, seu conteúdo refere-se especificamente aos conceitos a serem fixados e/ou aprendidos em determinada disciplina num determinado momento. [...] $\mathrm{A}$ capacidade de ajudar o aluno com problemas de memorização, fixação e verificação do conhecimento.

Porém, vem cheio de atrativos e animações que estimulam a criança a querer aprender. Krüger \& Krüger(2009), explicam o Tux Math sendo um jogo educativo para criança, composto pelas quatro operações auxiliando no processo de ensino-aprendizagem de forma lúdica. E descrevem que:

O jogo é uma espécie de Spacinvaders, onde meteoros são acompanhados por operações matemáticas e para destruí-los o educando terá que resolver os problemas. O personagem principal do jogo é o famoso pinguim Tux, que vai destruir todos os meteoros com raios laser, ativado pelas soluções matemáticas.

\section{Para a autora De Sousa(2009):}

O objetivo principal deste software é agilizar e aumentar o raciocínio matemático, pois os educandos são levados a brincar contra o computador e por conta disso, acabam desenvolvendo o raciocínio lógico matemático mental, pois as soluções terão 
que ser rápida e certa para que ganhem da máquina. Os resultados são surpreendentes, pois observa-se em sala de aula a aplicação do saber matemático em resoluções de problemas, pois os educandos aprendem brincando.

Durante o jogo as operações aritméticas (soma, subtração, divisão e multiplicação), caem do topo da tela e o jogador deve digitar rapidamente 0 resultado, caso contrário as operações vão descendo e se duas atingirem a casa o pinguim a primeira derrete-a e na segunda ele irá escapar, mostrando o valor da operação em cada caso. Ao digitar teclar Enter, se o resultado estiver correto, o pinguim lança um raio laser eliminando a operação proposta, e à medida que vai mudando os níveis, a velocidade com que as operações aritméticas caem aumenta e o jogo fica muito interessante, pois os cenários mudam constantemente. No decorrer do jogo o pinguim gesticula parecendo interagir com o usuário e esse em cada fase tem a possibilidade de resgatar os pinguins perdidos, para isso basta acertar vários cálculos seguidos.

Exemplos da interface do software:

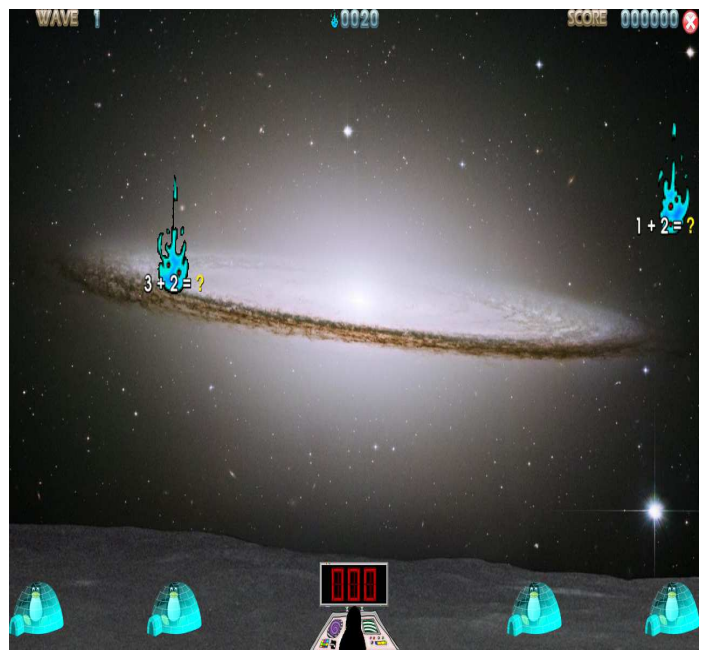

Figura 01: Adição de números de 1 a 3

Fonte: Software Tux of the Math Comand

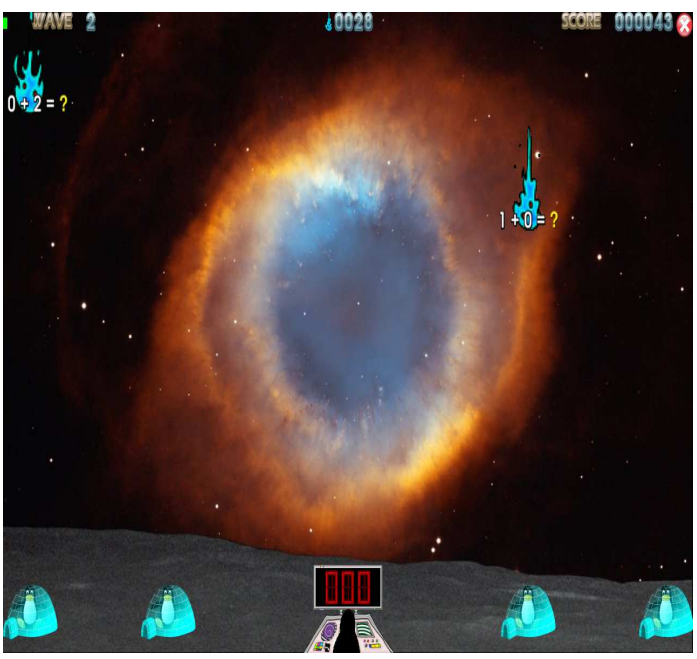

Figura 02: Adição de números de 0 a 10.

Fonte: Software Tux of the Math Comand

A partir dessa descrição e a da utilização desse software verificou-se que o mesmo está inserido num contexto de exercício e prática, caracterizados pelo processo instrucional com exigências de respostas pré-determinadas maximizando a efetividade de aprendizagem desse comportamento. E, 
portanto, indo ao encontro das metas deste trabalho e sendo um forte aliado na concretização da aprendizagem dos conteúdos.

Este projeto ocorreu concomitantemente ao andamento dos conteúdos da disciplina de Matemática, sendo trabalhado uma vez por semana durante uma hora aula. O qual favoreceu o desenvolvimento de atividades de adição, subtração, multiplicação e divisão, com exploração das habilidades para cálculos mentais praticados nas aulas de matemática.

Participaram do projeto 96 crianças, todas estudantes do $6^{\circ}$ anos de uma escola municipal de Novo Hamburgo. Para fazer parte desta pesquisa todas trouxeram termo de consentimento assinado pelos responsáveis e por elas aceitando participar do projeto e divulgação dos resultados.

Foram desenvolvidas atividades no laboratório de informática, durante 0 período de 20 semanas, com duração de uma hora semanal. Buscando-se otimizar o material físico já existente na escola, o que, desconsiderando o custo de manutenção do laboratório, com o uso do software gratuito, proporcionou um projeto com custo zero o que facilitou a viabilidade da execução do mesmo.

Para exemplificação das intervenções que foram feitas durante as atividades segue: $8 \times 5=$ ?, os alunos foram estimulados verbalmente a refletirem, o que/quem é a tabuada do 5 - a metade da tabuada do 10 - ou seja saber 8 × 5 é $(8 \times 10): 2=80: 2=40$. Sempre estimulando-os a novas estratégias e junto àqueles que ficavam contando nos dedos apresentou-se opções( $5 ; 10 ; 15 \ldots, 35$ e por fim $8 \times 5,40)$, o que no exemplo visto facilitou a resolução do cálculo e permitiu o aluno recorrer a informações por ele já sabido, deixando de ser algo apenas decorado.

\section{Cronograma das atividades}

\begin{tabular}{|c|l|}
\hline Aulas/Semana & \multicolumn{1}{c|}{ Atividades } \\
\hline \multirow{3}{*}{$1^{\text {a }}$ Aula } & Ambientação \\
& Adição com números de 1 a 3. \\
& Adição com números de 0 a 5. \\
& Subtração com números de 0 a 10. \\
\hline \multirow{2}{*}{$2^{\underline{a}}$ Aula } & Adição com números de 0 a 10. \\
& Adição com números de 0 a 15. \\
& Subtração com números de 0 a 10. \\
\hline
\end{tabular}




\begin{tabular}{|c|c|}
\hline Aulas/Semana & Atividades \\
\hline $3^{\text {a }}$ Aula & $\begin{array}{l}\text { Em duplas - porém cada um desenvolve a tarefa } \\
\text { Adição com números de } 0 \text { a } 20 \text {. } \\
\text { Subtração com números de } 0 \text { a } 20 \text {. }\end{array}$ \\
\hline $4^{\mathrm{a}}$ Aula & $\begin{array}{l}\text { Adição de números de dois algarismos } \\
\text { Subtração de números de dois algarismos }\end{array}$ \\
\hline $5^{\mathrm{a}}$ Aula & $\begin{array}{l}\text { Adição números perdidos } \\
\text { Revisão adição e subtração }\end{array}$ \\
\hline 6 Aula & $\begin{array}{l}\text { Torneio Cadete Espacial - com brindes } \\
\text { participação e desempenho }\end{array}$ \\
\hline $7^{a}$ Aula & $\begin{array}{l}\text { Multiplicação: números de } 0 \text { a } 3 \\
\text { Múltiplos de } 2 \text { - Divisão por } 2\end{array}$ \\
\hline $8^{\mathrm{a}}$ Aula & Múltiplos de 10 - Divisão por 10 \\
\hline $9^{\mathrm{a}}$ Aula & Múltiplos de 3 - Divisão por 3 \\
\hline $10^{\mathrm{a}}$ Aula & Múltiplos de 4 - Divisão por 4 \\
\hline $11^{\mathrm{a}}$ Aula & Multiplicação de 0 a 5 - Divisão de 1 a 5 \\
\hline $12^{\mathrm{a}}$ Aula & Múltiplos de 6 - Divisão por 6 \\
\hline $13^{\mathrm{a}}$ Aula & Múltiplos de 7 - Divisão por 7 \\
\hline $14^{\mathrm{a}}$ Aula & $\begin{array}{l}\text { Multiplicação de } 0 \text { a } 7 \\
\text { Revisão Adição e Subtração }\end{array}$ \\
\hline $15^{\mathrm{a}}$ Aula & $\begin{array}{l}\text { Torneio Sentinela e Defensor - com brindes } \\
\text { participação e desempenho }\end{array}$ \\
\hline $16^{\mathrm{a}}$ Aula & Multiplicação por 8 - Divisão por 8 \\
\hline $17^{a}$ Aula & Multiplicação por 9 - Divisão por 9 \\
\hline $18^{\mathrm{a}}$ Aula & Multiplicação de 0 a 10 - Divisão de 1 a 10 \\
\hline 19aa Aula & Revisão Multiplicação e Divisão \\
\hline $20^{\mathrm{a}}$ Aula & $\begin{array}{l}\text { Torneio - Jogo Personalizado - com brindes } \\
\text { participação e desempenho } \\
\text { Exploração Livre }\end{array}$ \\
\hline
\end{tabular}

Tabela 03: Cronograma das atividades desenvolvidas durante o projeto

\section{Resultados e discussões}

Nesse estudo constatou-se na prática o que muitos autores já afirmavam, que a utilização de ferramentas computacionais no processo V. $9 \mathrm{~N}^{\mathrm{o}}$ 2, dezembro, 2011 
educacional auxilia o trabalho docente, principalmente no ensino de matemática, possibilitando um aprendizado dinâmico e com um grau alto de motivação.

Segundo Alencar e Fleith(2003) citado por Fleith e Gontijo (2009), a mola mestra para que um indivíduo se dedique e se envolva em uma tarefa é o fato de ele estar motivado intrinsecamente. Sendo que os fatores motivacionais o levam a querer realizar as tarefas, ligados a um desejo de descoberta.

Para análise quantitativa e qualitativa dessa pesquisa foi utilizado a metodologia de Bardin(1977) e Bogdan e Biklen apud Araújo (2002).

No início e final do estudo foram aplicadas as seguintes perguntas aos alunos por um professor de outra área para dar maior liberdade as respostas:

1) Você gosta de Matemática?
( ) $\operatorname{sim}$
( ) mais ou menos
( ) não

2) Você é bom em Matemática?

( ) sim ( ) mais ou menos

( ) não

3) Você tem dificuldade para aprender Matemática?
( ) $\operatorname{sim}$
( ) mais ou menos
( ) não

\section{Quadro de respostas}

\begin{tabular}{|c|c|c|c|c|c|c|}
\hline Questão & sim & $\begin{array}{c}\text { mais ou } \\
\text { menos }\end{array}$ & não & \multicolumn{3}{|c|}{ Percentual } \\
\hline 1 & 12 & 10 & 74 & $11,52 \%$ & $9,6 \%$ & $71,04 \%$ \\
\hline 2 & 4 & 13 & 79 & $3,84 \%$ & $12,48 \%$ & $75,84 \%$ \\
\hline 3 & 71 & 16 & 9 & $68,16 \%$ & $15,36 \%$ & $8,64 \%$ \\
\hline
\end{tabular}

Tabela 04: Respostas antes do projeto.

\begin{tabular}{|c|c|c|c|c|c|c|}
\hline Questão & sim & $\begin{array}{c}\text { mais ou } \\
\text { menos }\end{array}$ & não & \multicolumn{3}{|c|}{ Percentual } \\
\hline 1 & 57 & 20 & 19 & $54,72 \%$ & $19,2 \%$ & $18,24 \%$ \\
\hline 2 & 44 & 21 & 31 & $42,24 \%$ & $20,16 \%$ & $29,76 \%$ \\
\hline 3 & 18 & 18 & 60 & $17,28 \%$ & $17,28 \%$ & $57,6 \%$ \\
\hline
\end{tabular}

Tabela 05: Respostas depois do projeto.

Abaixo podemos observar nos gráficos os resultados obtidos com 0 projeto. Dentro da sala de aula também observou-se essa mudança no número de alunos que passaram a interagir. No início quando perguntado algo, sempre tinha só um ou dois por turma que respondia, a medida que o projeto foi 
acontecendo cada vez mais alunos passaram a responder os questionamentos do professor.

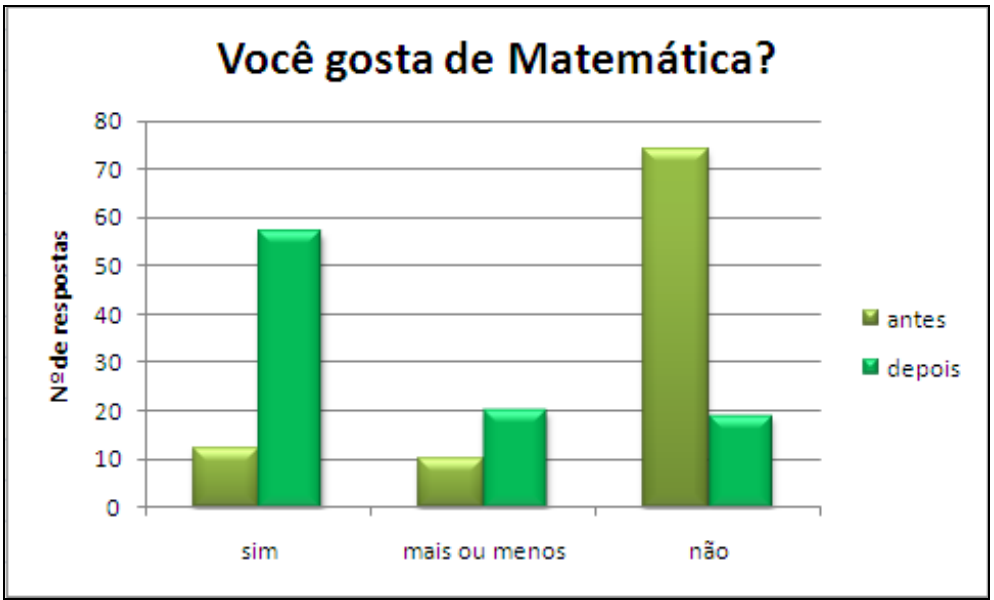

Gráfico 01: Você gosta de matemática.

No gráfico 01 , podemos constatar que depois do projeto a matemática passou a ser vista de outra maneira, muito mais alunos passaram a gostar dela, consequentemente dar aula tornou-se menos árduo, pois a aversão diminuiu.

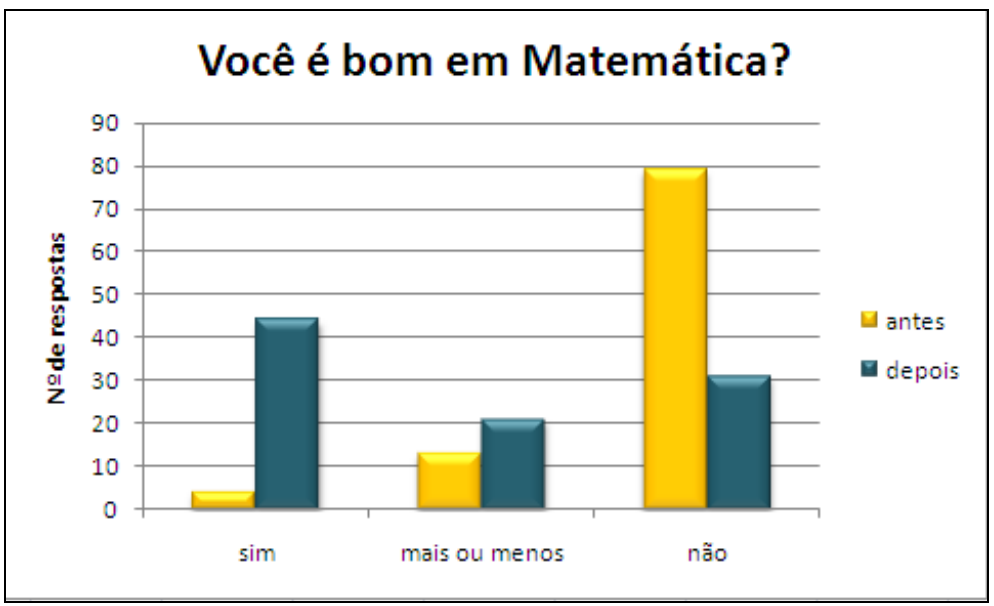

Gráfico 02: Você é bom em matemática.

Com a auto-estima elevada e a persepção de saber fazer e fazer corretamente os cálculos, mais alunos passaram a dizer que são bons em matemática. O que foi constado várias vezes na fala de alunos:

“... Eu era muito ruim em matemática, não sabia nada, depois que comecei a jogar o jogo do pinguim não erro nada, fiquei inteligente..."

"...tou craque, fera em matemática, sou quase o melhor da sala, mais uns dias no tux math eu vou ser mais inteligente que o fulano" 


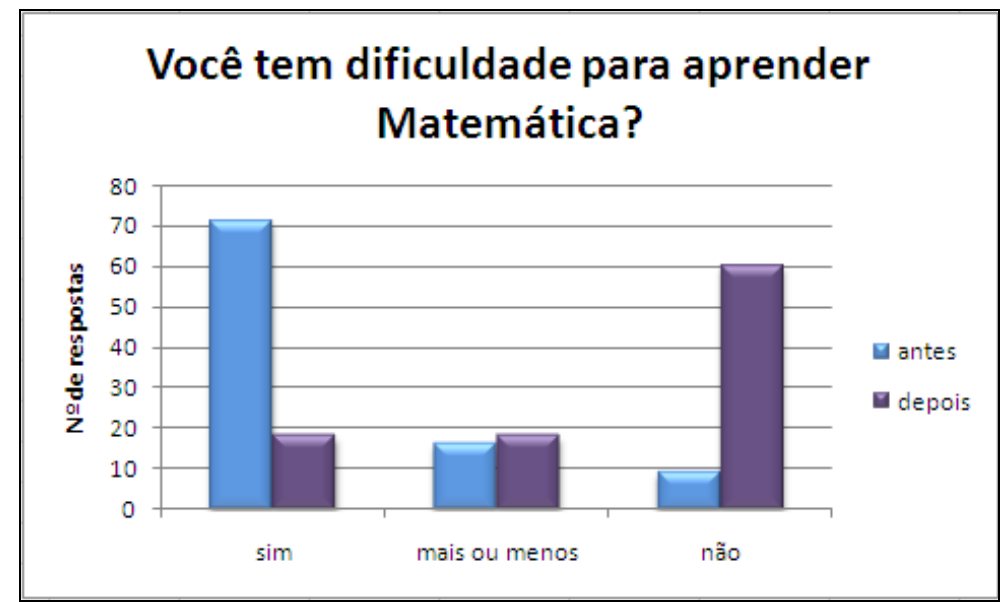

Gráfico 03: Você tem dificuldade para aprender matemática.

Do gráfico 03, podemos concluir que os alunos motivados e com menos aversão a matemática começaram aprende mais facilmente $\mathrm{e}$ consequentemente enfrentar menores dificuldades nessa disciplina.

Esses resultados nos mostram o quanto o autoconceito dos alunos mudou para melhor, e que o projeto foi ao encontro de Bonilla (1995) citada por Bona (2009) que afirmava ser possível trabalhar numa linha construtivista de aprendizagem utilizando recursos da tecnologia de informação.

\begin{abstract}
para que um software promova realmente a aprendizagem deve estar integrado ao currículo e às atividades de sala de aula, estar relacionado àquilo que o aluno já sabe e ser bem explorado pelo professor. O computador não atua diretamente sobre os processos de aprendizagem, mas apenas fornece ao aluno um ambiente simbólico onde este pode raciocinar ou elaborar conceitos e estruturas mentais, derivando novas descobertas daquilo que já sabia.
\end{abstract}

No entanto, o professor deve estar atento para que o jogo não seja apenas um processo de memorização de cálculos, apesar das atividades serem comportamentalistas, o professor pode tornar a aprendizagem significativa e apoiar o aluno na construção da aprendizagem com recursos além desse.

\title{
Conclusões e considerações para novos estudos
}

Ao final do projeto os objetivos foram alcançados quanto à questão da motivação, em relação ao aprendizado a evolução foi muito grande, mas ainda deve-se continuar com outras formas de reforço e recuperação, pois as 20 semanas não foram suficientes para sanar lacunas de alguns alunos e aptos as exigências de um 6ํano. 
Destacamos que ao trabalhar com o Tux Math of Comand, devemos estimular o aluno a pensar de forma autônoma e crítica, refletindo sobre suas ações lógico-matemáticas, com isso não estaremos expondo conceitos matemáticos e sim possibilitando o desenvolvimento de conceitos. Nesse sentido Kami (1990) destacava que:

o objetivo para "ensinar" o número é o da construção que a criança faz da estrutura mental de número. Uma vez que esta não pode ser ensinada diretamente, o professor deve priorizar o ato de encorajar a criança a pensar ativa e autonomamente em todos os tipos de situações. Uma criança que pensa ativamente, à sua maneira, incluindo quantidades, inevitavelmente constrói o número. A tarefa do professor é a de encorajar o pensamento espontâneo da criança, o que é muito difícil porque a maioria de nós foi treinada para obter das crianças, a produção de respostas "certas".

Finalizando queremos salientar que este software educativo também pode ser utilizado para o estudo dos números negativos, das frações e da decomposição em números primos. Mas sempre atentos ao que Lara (2005) citado por Gonçalves (2010) destaca:

Assim, se concebermos o ensino da Matemática como sendo um processo de repetição, treinamento e memorização, desenvolveremos um jogo apenas como sendo um outro tipo de exercício. Mas, se concebermos esse ensino como sendo um momento de descoberta, de criação e de experimentação, veremos o jogo não só como um instrumento de recreação, mas, principalmente, como um veículo para a construção do conhecimento.

\section{Referências Bibliográficas}

ARAÚJO, I. C. A disciplina de matemática e o fracasso escolar na 5a série do Ensino Fundamental de uma escola de rede municipal de Campo

Grande - MS. Disponível em:<http://www.sbem.com.br/files/ix_enem/ Comunicacao_Cientifica/Trabalhos/CC63707 578100T.doc>. Acesso em: 14 set 2010.

ARAÚJO, J. L. Cálculo, tecnologias e modelagem matemática: as discussões dos alunos. Rio Claro: UNESP, 2002. Tese de doutorado. BARDIN, L. Análise de conteúdo. Lisboa: Edições 70, Ltda, 1977.

BONA, B. O. Análise de softwares educativos para o ensino de matemática nos anos iniciais do ensino fundamental. Revista Experiência em Ensino de Ciências. Porto Alegre. v.4. n.1. 2009.

CAMPOS, F. C. A., "Hipermídia na Educação: Paradigmas e avaliação da qualidade". COPPE/Sistemas, UFRJ, Rio de Janeiro, 1994. Tese de M.Sc. 
CAMPOS, F. C. A., COSTA, R. M., SANTOS, N. Ambientes Computacionais na Educação. Disponível em: <http://www.lanteuff.org/ moodle> Acesso em:

20 Set. 2010.

DE SOUSA, R. Tux Math - as quatro operações matemáticas. Colloquium Exactarum, vol. 1, n. Especial, 2009

FABRE, M. C. J. M.; TAROUCO, L. M. R.; TAMUSIUNAS, F. R. Reusabilidade de objetos educacionais. RENOTE - Revista Novas Tecnologias na

Educação. Porto Alegre: CINTED(UFRGS), v. 1, n.1, 2003.

FLEITH, D. S; GONTIJO, C. H...Motivação e criatividade em matemática: um estudo comparativo entre alunas e alunos de ensino médio. ETD - Educação Temática Digital, Campinas, v.10, n.esp.,2009 GONÇALVES, M. L. C. O uso do jogo on-line como possibilidade de aprendizagem da Matemática. RENOTE - Revista Novas Tecnologias na Educação. Porto Alegre: CINTED(UFRGS), v. 8, n.3, 2010.

KAMII, Constance. A criança e o número. Tradução: Regina A. de Assis. 26 ed. Campinas, SP, Papirus, 1990.

KRÜGER, R.; KRÜGER, F. É divertido educar: Guia pedagógico. Pandorga GNU/Linux. 01. ed. Porto Alegre/RS: Gênese Editora, 2009.

STRELOW, M. Z; DEL PINO, M. A. B. A exclusão escolar e matemática no Ensino Fundamental. Disponível em:

<http://www.ufpel.tche.br/cic/2009/cd/pdf/CH/CH_01336. pdf>. Acesso em: 14 set 2010. 